\title{
Commentary: Variability matters-lessons for quality and health policy
}

\author{
Robert B. Hawkins, MD, MSc, and J. Hunter Mehaffey, MD, MSc
}

\author{
From the Division of Thoracic and Cardiovascular Surgery, University of Virginia, Charlottesville, Va. \\ Disclosures: Authors have nothing to disclose with regard to commercial support. \\ Received for publication May 10, 2019; accepted for publication May 13, 2019; available ahead of print June 14 \\ 2019. \\ Address for reprints: Robert B. Hawkins, MD, MSc, Department of Thoracic and Cardiovascular Surgery, Uni- \\ versity of Virginia, P.O. Box 800679, Charlottesville, VA 22908 (E-mail: rbh6x@ virginia.edu). \\ J Thorac Cardiovasc Surg 2020;159:1245-6 \\ $0022-5223 / \$ 36.00$ \\ Copyright (c) 2019 by The American Association for Thoracic Surgery \\ https://doi.org/10.1016/j.jtcvs.2019.05.004
}

In this issue of the Journal, Greason and colleagues ${ }^{1}$ provide a detailed look at the variability within the Placement of Aortic Transcatheter Valves-2A (PARTNER-2A) trial. Variability is an often-overlooked but incredibly informative measure of quality. One reason for this is the complex statistics required that are neither common nor intuitive. In this study, the authors presented their results using more intuitive metrics such as hazard ratios. The other reason for limited variability analyses is that they require large sample sizes or high event rates.

Within the PARTNER-2A trial, there was an impressive amount of inter-site variability. There was a 4-fold range in relative risk of mortality across participating sites, for both transcatheter aortic valve replacement (TAVR) and surgical aortic valve replacement (SAVR). Although this variability extended to stroke after SAVR, there was no identified variability for TAVR in this smaller population of only clinical trial patients. This point highlights the importance of big data, where the coordination of the Society of Thoracic Surgeons (STS) National Database and Transcatheter Valve Therapies database is going to be critical to the future success of TAVR. When the sample size is small or event rates are low, deviation from high-quality care is difficult to identify and therefore unable to be corrected. The inclusion of more than $99 \%$ of cardiac practices within the STS database also represents real-world results, rather than hand-picked sites that gave the trial the best chances of a success. Finally, much of the variability noted came after 30 days. The importance of post-30-day care and outcomes is becoming ever more evident, with meaningful patient outcomes now being measured at a year and alternative payment models bundling 90-day coverage. . $^{2,3}$ Although there is room for improvement in the current STS databases, they present an opportunity to use highquality clinical data to craft health policy decisions that are going to be made with or without our participation.

Drivers of inter-site variability included case mix and volume, with $73 \%$ of the variability in mortality after

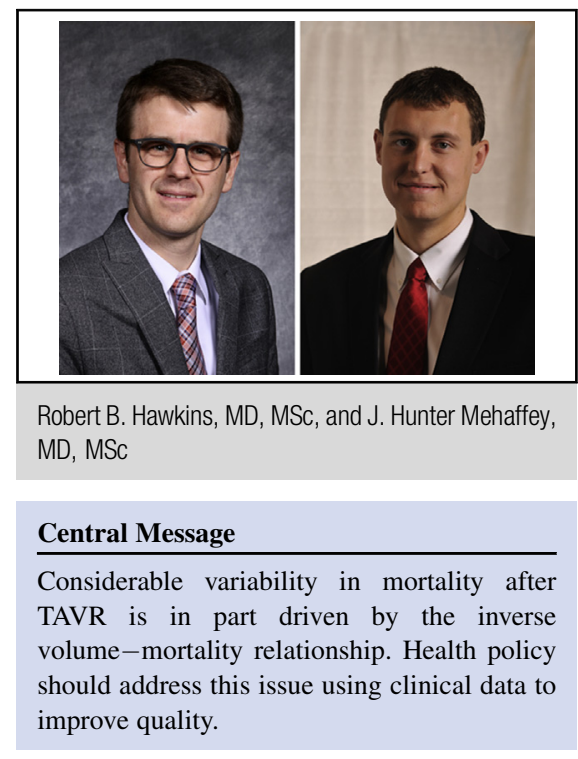

See Article page 1233 .

TAVR. This is significantly more than for SAVR (37\%), supporting procedural volume requirements for TAVR programs. In addition, low volume was associated with early death. These results from PARTNER-2A are corroborated by recently published data from the Transcatheter Valve Therapies database showing a $19.45 \%$ relative risk reduction between highest and lowest TAVR volume quartiles. ${ }^{4}$ In addition, there was considerable variability in lowvolume centers, with mortality estimates ranging from $0 \%$ to $>12.5 \%$. The driver of this trend is likely that higher-volume programs have greater resources at their disposal, allowing for a more robust multidisciplinary advanced valve team. This also impacts case mix, where robust preoperative patient selection and optimization likely influences the variability seen. Because these teams work across both surgical and interventional procedures, it is not surprising that limited intra-site variability was noted. The relationship between TAVR and SAVR outcomes could also have policy implications from a regulatory standpoint. These findings are also consistent with the finding that hospitals tend to have similar valve and coronary outcomes. ${ }^{5}$ A strong team, whether that is the advanced valve team or the cardiac surgical team, is critical to achieving high-quality care. 


\section{References}

1. Greason KL, Blackstone EH, Rajeswaran J, Lowry AM, Svensson LG, Webb JG, et al. Inter- and intrasite variability of mortality and stroke for sites performing both surgical and transcatheter aortic valve replacement for aortic valve stenosis in intermediate-risk patients. J Thorac Cardiovasc Surg. 2020; 159:1233-44.e4.

2. Hawkins RB, Mehaffey JH, Yount KW, Yarboro LT, Fonner C, Kron IL, et al. Coronary artery bypass grafting bundled payment proposal will have significant financial impact on hospitals. J Thorac Cardiovasc Surg. 2018;155:182-8.
3. Charles E, Mehaffey J, Hawkins R, Burks S, McMiurry T, Yarboro L, et al. One year patient-reported outcomes following cardiac surgery. Ann Surg. 2019 [In press].

4. Vemulapalli S, Carroll JD, Mack MJ, Li Z, Dai D, Kosinski AS, et al. Procedural volume and outcomes for transcatheter aortic-valve replacement. $N$ Engl J Med. 2019;380:2541-50.

5. Johnston LE, Downs EA, Hawkins R, Quader M, Speir A, Rich J, et al. Good at one or good at all? Variability of coronary and valve operation outcomes within centers. Ann Thorac Surg. 2018;105:1678-83. 